Brit. J. industr. Med., 1952, 9, 19.

\title{
A STUDY OF THE CONDITIONS UNDER WHICH METHANOL MAY EXERT A TOXIC HAZARD IN INDUSTRY
}

\author{
BY \\ G. LEAF and L. J. ZATMAN \\ From the Physiology Department, the University of Manchester
}

(RECEIVED FOR PUBLICATION AUgUST 14, 1951)

All lower aliphatic alcohols have rapid narcotic effects the degree of which, as Richardson (1869) showed, increases with molecular weight of the alcohols in the homologous series. Methanol shares with its homologues this acute narcotic action but is anomalous in that it also exerts characteristic chronic toxic effects, probably due to the slowness with which it is eliminated from the body and the toxicity of the products of its metabolic oxidation, formaldehyde and formic acid. Owing to this difference the toxic effects of methanol are more insidious than those of its homologues, and there is therefore a definite hazard associated with the now extensive industrial use of methanol. The danger is increased by the tendency to confuse methanol with ethanol and use it as a beverage. This unfortunate error has caused many serious outbreaks of poisoning in the past. McGregor (1943), Jacobson, Russell, Grimm, and Fox (1945), Kaplan and Levreault (1945), Røe (1946), and Chew, Berger, Brines, and Capron (1946) describe recent examples.

The danger from its use in industry was first noted by McFarlan in 1856 (McCord, 1931), and numerous cases of industrial poisoning have been reported since then (see von Oettingen, 1943; Hamilton, 1925 ; Browning, 1937, for summaries of the literature). More recently, awareness of the danger and consequent caution have greatly reduced the number of cases in spite of a great increase in the use of methanol, and with reasonable care it can be used quite safely in industry. During the recent war a rapid expansion in the use of methanol was envisaged with the corresponding danger of a renewal of the hazard (Humperdinck, 1941). The present work was therefore undertaken in order to establish accurate safety limits for exposure to methanol.

This problem had previously stimulated a certain amount of experimental work. It was early shown that exposure of rats, mice, dogs, and cats to methanol vapour may cause death (Tyson and Schoenberg, 1914; Loewy and von der Heide, 1914 ; Macht, 1920 ; Weese, 1928) and that in some cases death may be delayed until some time after termination of the exposure (Loewy and von der Heide, 1914 ; Witte, 1933). The conditions employed in these earlier experiments were generally rather drastic, but more carefully controlled experiments have been carried out by McCord (1931) using rats, rabbits, and monkeys, and by Yant and Schrenk (1937), Yant, Schrenk, and Sayers (1931), and Sayers, Yant, Schrenk, Chornyak, Pearce, Patty, and Linn (1944), using guinea-pigs, dogs, and monkeys. Full reports of these experiments are not available in this country, but McCord concluded that continued exposure to a vapour concentration of 1,000 p.p.m. or exposure to conditions where $31 \mathrm{ml}$. of methanol may be absorbed in 41 hours would be dangerous. Sayers and others (1944) report that exposure to 500 p.p.m. for eight hours a day or exposure to 9,000 p.p.m. for short periods (less than five minutes) eight times a day was not injurious to dogs.

McCord (1931) also demonstrated with monkeys that sufficient methanol can be absorbed through the skin to cause death. Rost and Braun (1926) and Yant and others (1931) discount the practical importance of this route of absorption, and indeed conditions akin to those used experimentally by McCord, which involved the application of methanolsoaked pads under a gas-tight cover, are hardly likely to be encountered in industrial practice.

Results obtained in experiments with animals have been used to estimate safety limits of exposure to methanol for man. It has been noted that McCord suggested that conditions where $31 \mathrm{ml}$. of methanol may be absorbed in 41 hours $(18 \mathrm{~g}$. $/ 24$ hours) are dangerous. Widmark (1933) calculated from the determined rates of elimination of methanol 
and ethanol by rabbits and ethanol by man that $34 \mathrm{~g}$. of methanol could be safely eliminated in 24 hours. By similar comparison between dog and man Neymark (1936) amended this value to 14.4 g. 24 hours, a result more in keeping with the findings of McCord (1931).

The application to human problems of results obtained in experiments with animals always requires caution. Laboratory animals show wide variations in sensitivity to methanol (Rost and Braun, 1926 ; Scott, Helz, and McCord, 1933) especially when this is inhaled as the vapour (Loewy and von der Heide, 1914 ; McCord, 1931). Man appears to be much more sensitive than the smaller mammals to the effects of this poison. Values for the minimum acutely lethal dose for small laboratory animals vary from $4.7 \mathrm{~g} . / \mathrm{kg}$. for the cat (Macht, 1920 ) to $14 \mathrm{~g} . / \mathrm{kg}$. for the rabbit (Munch and Schwartze, 1925 ; Nicloux and Placet, 1912). For man the lethal dose is estimated by Røe (1943) and Poulsson (1941) as less than $1 \mathrm{~g}$. $/ \mathrm{kg}$. Data from fatalities caused by drinking methanol suggest a wide variation in individual sensitivity in man, some individuals dying after consumption of less than 30 g. (Røe, 1946 ; Ziegler, 1921 ; Egg, 1927) whilst others have consumed $150 \mathrm{~g}$. without ill effect (Røe, 1946 ; Chew, Berger, Brines, and Capron, 1946; Uhthoff, 1915). Røe suggests that this variation is largely due to the simultaneous consumption of varying amounts of ethanol. but the report of Chew and others (1946) suggests that this is not entirely so.

The safety limits quoted above must therefore be accepted with reserve in the absence of data obtained with human subjects. The aim of the present work was to obtain such data. The experiments were designed to determine the minimum conditions under which accumulation of methanol may occur, that is, conditions where the amount of methanol absorbed during a normal working period of eight hours would not be completely eliminated* before the beginning of the next working period 16 hours later. This requires a knowledge of the processes of absorption and elimination of methanol in man. Previous work on the elimination of methanol has been carried out with animals other than man and has yielded conflicting results. Neymark (1936) and Neymark and Widmark (1936) claimed that the rate of elimination by dogs was independent of the concentration in the body. Haggard and Greenberg (1939), however, concluded that with rats and dogs the rate of elimination was proportional to the concentration of methanol in the body.

* Throughout this paper the term "elimination" is used to indicate the disappearance of methanol from the body without any assump tions as to the mechanism of its removal. Where specific mechanisms, such as urinary excretion, are considered, these are specified.
A similar confusion is found in the literature on the elimination of ethanol (Eggleton, 1940 ; Haggard and Greenberg, 1934 ; Carpenter, 1940).

Knowledge of the absorption of methanol by inhalation of the vapour is even more scanty. The reports of Loewy and von der Heide (1914) and Yant and Schrenk (1937) contain a certain amount of information on the rate of accumulation by rats and dogs, but as their experiments were carried out at high vapour concentrations the results are of little value for the present purpose. Further, as the rate of absorption is largely conditioned by the rate of respiration, which varies widely with the size of the animal, one would expect a large difference between man and the lower animals in respect of absorption by inhalation.

Absorption and elimination of methanol were therefore studied with human subjects. Though such an investigation can only be carried out under laboratory conditions, it is desirable to test the conclusions under conditions of industrial practice. We were therefore glad of an opportunity to investigate conditions prevailing in the methanol synthesis plant of Messrs. Imperial Chemical Industries (Fertiliser and Synthetic Products) at Billingham.

The Effect of Ethanol on Methanol Poisoning

While this work was in progress a report by $R ø e$ (1943) became available in which case records of 16 patients suffering from methanol poisoning were described. From these cases Røe concluded that the injurious effects of methanol were reduced by the simultaneous ingestion of ethanol. Subsequent and more extensive observations have confirmed this view (Røe, 1946; Dérobert and Hadengue, 1949 ; Agner, Höök, and von Porat, 1949). It appeared that ethanol might act favourably by inhibiting the conversion of methanol into some more toxic product, e.g. formaldehyde or formate, and it seemed likely that such inhibition would be reflected in an increased output of unchanged methanol. The effect of ingestion of ethanol on the elimination of a standard dose of methanol was therefore studied. Striking effects were observed and it was shown in vitro that ethanol exerts a powerful inhibitory effect on the oxidation of methanol by liver alcohol dehydrogenase. A preliminary note of this work has already been published (Zatman, 1946).

\section{Methods}

Determination of Methanol.- The method used was that originally proposed by Denigès (1910) as modified by Wright (1927). It involves oxidation by means of acid permanganate to formaldehyde which is then determined colorimetrically with a modified Schiff's 
reagent. It was found that the sensitizing effect of ethanol on the determination increased with increase in the concentration of ethanol to a maximum between $1.2 \%$ and $1.8 \%$ ethanol. Solutions under test were therefore always adjusted to contain approximately $1.5 \%$ ethanol before analysis. This gave maximal sensitivity and eliminated the possibility of errors due to the presence of small amounts of ethanol in the test samples. In contrast to the experience of Wright it was found that both stages of the estimation were sensitive to temperature variations. The entire process was therefore carried out in a thermostat at $25^{\circ} \mathrm{C}$. Optical densities were determined with the Spekker absorptiometer using the yellowgreen filter. With these modifications concentrations of methanol up to $15 \mathrm{mg}$. per $100 \mathrm{ml}$. could be determined to within $3 \%$.

For the determination of methanol in urine, $10 \mathrm{ml}$. of the urine were treated with $2 \mathrm{ml} .4 / 3 \mathrm{NH}_{2} \mathrm{SO}_{4}$ and $1 \mathrm{ml}$. $10 \%$ sodium tungstate, and the mixture distilled in an all-glass apparatus (Nicloux, Le Breton, and Dontcheff, 1934). The first $5 \mathrm{ml}$. of distillate were collected in a graduated flask and analysed for methanol as described above. In 15 control determinations the recovery of added methanol was $96.4 \pm 1.2 \%$ (standard error). Normal urine from six human subjects gave small blank values, the mean for 20 determinations being $0.3 \mathrm{mg}$. per $100 \mathrm{ml}$. expressed as methanol. As the experiments carried out were of a comparative nature, this blank value was unimportant. Tests for the presence of formaldehyde in the urine distillates were consistently negative.

For the determination of methanol in blood, deproteinization was carried out by the usual Folin-Wu method, and 10 or $15 \mathrm{ml}$. of the filtrate were distilled. As in the case of urine, $5 \mathrm{ml}$. of distillate were collected and used for the estimation. Recovery of added methanol was $94-96 \%$, and normal blood (cat or human) gave no appreciable blank value.

For the determination of methanol in air, the air was drawn through a train of four drechsel bottles, each containing $150 \mathrm{ml}$. of water, in series with a gas meter. The conten's of the bottles were then mixed and the methanol content determined as above. Recovery of methanol evaporated into the air stream was 96-98\% at methanol concentrations of $1-10 \mathrm{mg}$. per 1 . and the rate of flow about 21 . per minute.

Assessment of Methanol Content of the Body.-In a study of this kind with human subjects the toxicity of the methanol precludes the use of large doses. The concentration of methanol in the body water being therefore rather small, the analysis of urine, which is readily available in comparatively large quantities, is a more convenient and practicable index of the concentration of methanol than is analysis of blood. According to Yant and Schrenk (1937), methanol administered to experimental animals becomes uniformly distributed about the tissues of the body according to their relative water content. The same has been demonstrated for ethanol by Nicloux (1934) and Harger, Hulpieu, and Lamb (1937). Further, Haggard, Greenberg, Carroll, and Miller (1940), and Eggleton (1942) have provided evidence that after giving ethanol to man there is a constant relationship between blood concentration and concentration in urine contemporaneously secreted. This is determined by the relative water content of the two fluids, the kidney having no selective action on the distribution of the alcohol between them. Further, to justify the use of urinary methanol concentration as an index of methanol concentration throughout the body water, the constancy of the blood/urine relationship was confirmed using cats as experimental subjects.

The cat was anaesthetized with chloralose $(80 \mathrm{mg}$. per kg.) and the bladder emptied and cannulated, the bladder contents being kept as a control sample. A suitable dose of methanol (100-270 mg. per kg.), diluted with Ringer solution, was then injected into the femoral vein and samples of blood from the carotid artery and of urine were taken at intervals of 30 to 60 minutes for four to five hours. The methanol concentration in each sample was determined as described above. To promote an adequate rate of urine flow it was found expedient to give injections of $5 \mathrm{ml}$. of $7 \cdot 5 \%$ sodium sulphate via the femoral vein at quarter-hour intervals.

Experiments on Man.-The subjects were five adult males. The dose of methanol which varied from 2.5 to $7.0 \mathrm{ml}$. (29-84 mg. $/ \mathrm{kg}$.) was diluted to $100 \mathrm{ml}$. with water and taken immediately after emptying the bladder before breakfast. Urine was collected after one and two hours, and then every two hours for a period which varied in different experiments from 11 to 16 hours. The total volume at each voiding was noted and the urines were preserved with a small amount of $\mathrm{H}_{2} \mathrm{SO}_{4}$ and kept at $4^{\circ} \mathrm{C}$. until the methanol concentrations had been determined. Pure methanol and clinical absolute ethanol (benzene-free) were used throughout the experiments.

Inhalation Experiments.-The subject was exposed to a known concentration of methanol vapour for two to four hours and the absorption* of methanol was followed by analysis of urine voided at frequent intervals. The exposures were carried out in a small room $(22.9 \mathrm{cu} . \mathrm{m}$. capacity) with no windows and two doors separated by an air lock. The doors were felted at the edges to prevent the escape of methanol. The desired concentration of methanol was established in the chamber by rapid evaporation of the calculated quantity of methanol by allowing it to drip from a burette on to a hot plate in the draught of an electric fan. The subject then entered the chamber, and the methanol vapour concentration was maintained at a constant level by continuous evaporation of methanol at a predetermined rate. The air of the chamber was kept in motion by the electric fan, and in each experiment the concentration of methanol was determined at half-hour intervals by the method outlined above. In practice it was found that the methanol concentration in the chamber could easily be kept within $10 \%$ of the mean.

*It will be noticed that the " absorption" measured is really the balance of methanol absorbed minus that eliminated during the period of exposure. The term accumulation more accurately describes the overall process, but to avoid confusion this term is reserved for the long term accumulation of methanol after repeated intermittent exposures. 
The bladder was emptied immediately before entering the chamber and at intervals of approximately 30 minutes during the experiment. The urine was collected in stoppered bottles and the methanol content determined as described above. To promote the flow of urine, water and coffee were taken before the experiment.

\section{Results}

Relation between Concentrations of Methanol in Blood and Urine.-The results of two experiments on cats are shown graphically in Fig. 1. The con-

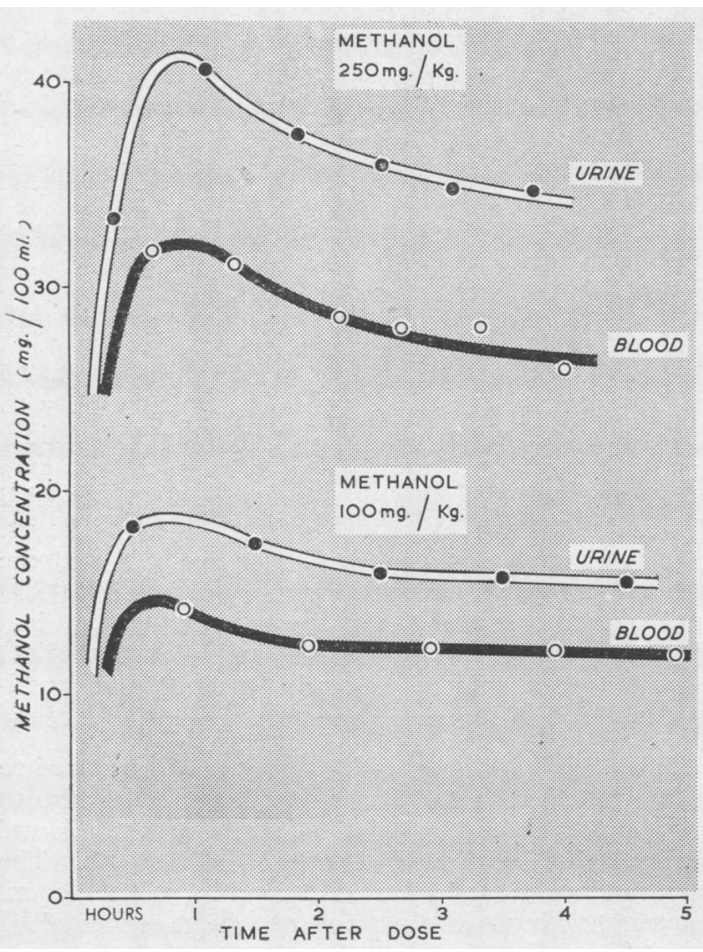

FIG. 1.-The concentration of methanol in blood and urine of the cat after methanol.

centrations of methanol in blood and urine follow a similar course. The constancy of the ratio (concentration in urine : concentration in blood) is seen in Table 1. The mean value of the ratio was $1 \cdot 29$, agreeing well with the figure of 1.3 found by Haggard and others (1940) for ethanol in man. The relationship was further checked by a few determinations of the methanol content of blood in human subjects, during the elimination of methanol. The results are given in Table 2 . The values for the ratio (concentration in urine : concentration in blood) are based on single determinations and show more variation than in the experiments with cats, probably due to the difficulty of accurately estimating such low concentrations of methanol in
TABLE 1

RELATION BETWEEN METHANOL CONCENTRATION IN BLOOD AND URINE IN THE CAT

\begin{tabular}{c|c|c|c|c}
\hline $\begin{array}{c}\text { Cat } \\
\text { No. }\end{array}$ & $\begin{array}{c}\text { Dose of Methanol } \\
\text { (mg. per kg.) }\end{array}$ & $\mathrm{CB}^{*}$ & $\mathrm{CU}^{*}$ & $\mathrm{CU} / \mathrm{CB}$ \\
\hline $3 \mathrm{H}$ & 100 & $12 \cdot 15$ & $15 \cdot 7$ & $1 \cdot 29$ \\
\hline $4 \mathrm{H}$ & 250 & $27 \cdot 0$ & $35 \cdot 2$ & $1 \cdot 30$ \\
\hline $5 \mathrm{H}$ & 250 & $27 \cdot 5$ & $35 \cdot 0$ & $1 \cdot 27$ \\
\hline $1 \mathrm{H}$ & 270 & $31 \cdot 7$ & $41 \cdot 2$ & $1 \cdot 30$ \\
\hline & & & mean & $1 \cdot 29$ \\
\hline
\end{tabular}

* Each value for the blood (CB) is the mean of the last four determinations in each experiment, and each value for the urine (CU) the mean of the last three determinations. The concentrations are expressed in $\mathrm{mg}$. per $100 \mathrm{ml}$. blood or urine.

TABLE 2

RELATION BETWEEN METHANOL CONCENTRATION IN BLOOD AND URINE IN MAN

\begin{tabular}{l|c|c|c|c|c}
\hline Subject & $\begin{array}{c}\text { Dose of } \\
\text { Methanol } \\
\text { (mg. per } \\
\text { kg.) }\end{array}$ & $\begin{array}{c}\text { Time } \\
\text { after } \\
\text { Dose } \\
\text { (hr.) }\end{array}$ & CB & CU & CU : CB \\
\hline H.S.R. & 71 & 2.5 & 5.33 & 7.5 & 1.41 \\
\hline L.J.Z. & 83.5 & 2 & 7.6 & 9.2 & 1.21 \\
\hline G.L. & 71 & 3 & 4.7 & 6.40 & 1.36 \\
\hline & & 5 & 3.2 & 4.1 & 1.28 \\
\hline- & & 6.75 & 8.4 & 1.24 \\
\hline
\end{tabular}

Each value for blood (CB) represents a single determination, the value for urine (CU) at the same time being obtained from the corresponding elimination curve plotted as in Fig. 2 . The concentrations are expressed in mg. per $100 \mathrm{ml}$. of blood or urine.

blood. Taken together, however, the results in Tables 1 and 2 suggest that, provided the bladder is emptied fairly frequently, the urinary methanol concentration is a reliable index of the concentration of methanol in the body water during the period of secretion.

Elimination of Methanol.-The variation of urinary methanol concentration with time after the ingestion of three different doses of methanol by the same subject is shown in Fig. 2. These results are typical of a number of experiments carried out with different subjects. Evidence has been presented in the foregoing section of this paper which justifies the assumption that the urinary methanol concentrations may be taken fairly to represent the average methanol concentrations in the body-water during 


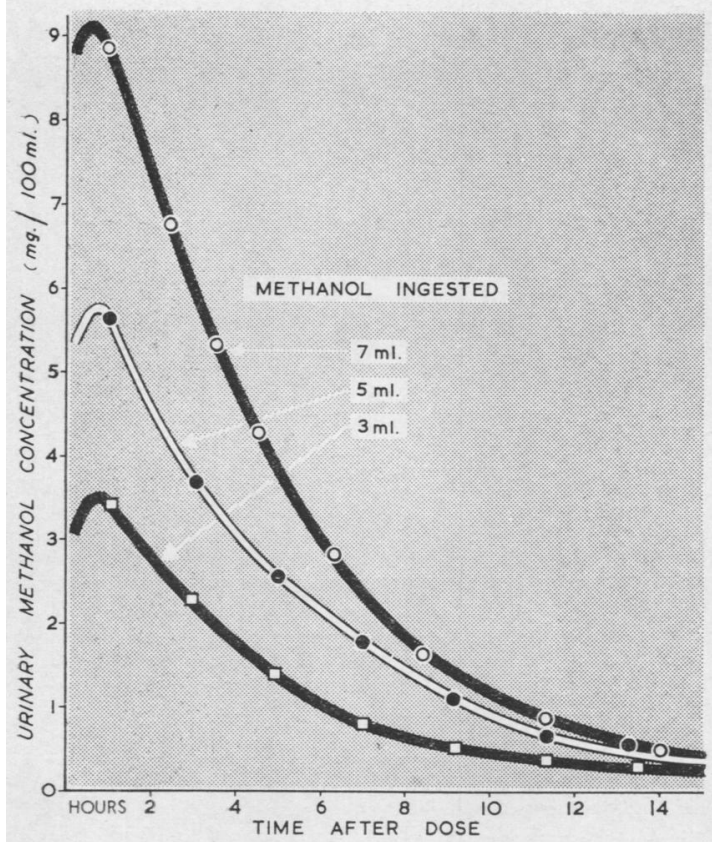

Fig. 2.-The concentration of methanol in human urine after ingestion of methanol. Subject, G.L., weight $78.5 \mathrm{~kg}$.

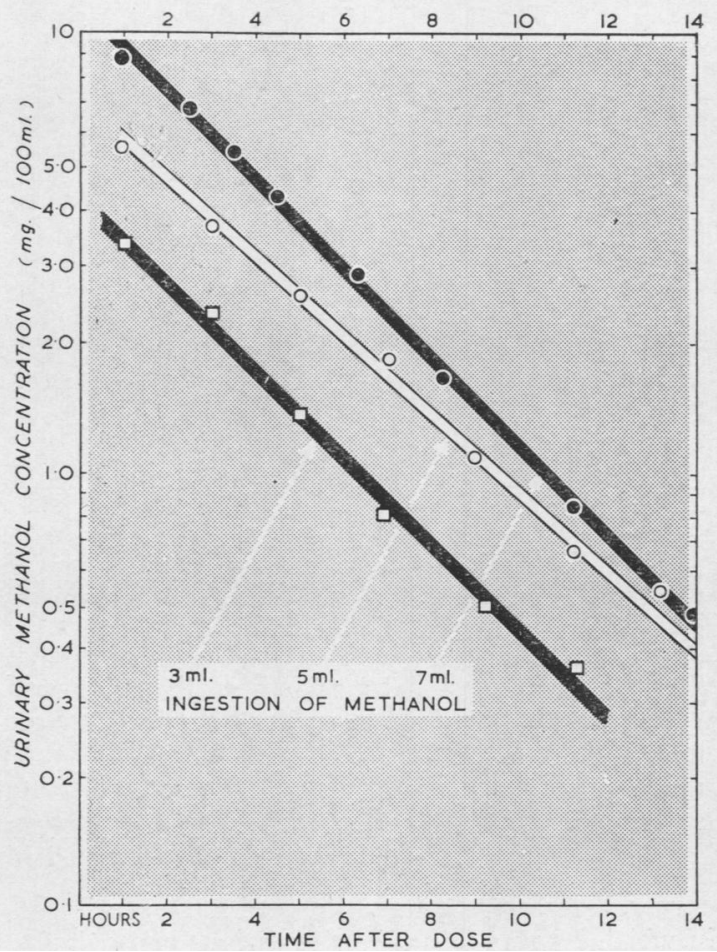

FIG. 3.-The concentration of methanol in urine after ingestion of methanol plotted on a half-log. scale. Data as for Fig. 2. the period of secretion of each specimen of urine. The curves indicate that the absorption of methanol was rapid, as was to be expected with small doses on an empty stomach. After reaching a maximum within about one hour, the concentration fell rapidly at first, then more slowly, until control values were reached again after 13 to 16 hours. When the logarithms of urinary concentrations are plotted against time, as in Fig. 3, the points conform closely to straight lines. The curves in Fig. 3 may be represented by an expression similar to that derived by Gaddum (1944), i.e. $\log \mathrm{C}=\log \mathrm{C}_{\mathrm{o}}-\mathrm{kt}$

where $\mathrm{C}_{\circ}{ }^{*}$ and $\mathrm{C}$ are the urinary methanol concen-



Fig. 4.-Absorption of methanol by inhalation of the vapour. Subject, L.J.Z.

trations at zero time and $t$ hours respectively and $k$ a constant for the individual. The values of $\mathbf{k}$ for subject G.L. calculated from the data plotted in Fig. 3 were 0.104, 0.099, and 0.094 for the three dosage levels (C and $C_{\circ}$ expressed as $\mathrm{mg}$. per $100 \mathrm{ml}$. urine and $t$ in hours). Values obtained from similar experiments with H.S.R. and L.J.Z. were 0.097, $0 \cdot 102,0 \cdot 106$, and $0 \cdot 108,0.099,0 \cdot 101$ respectively. Thus the course of methanol elimination under these conditions was exponential and the rate of elimination at any time was proportional to the methanol concentration in the body at that time.

* $C_{\circ}$ is the hypothetical value for the concentration of methanol in the urine excreted at zero time if the absorption and distribution of the methanol were instantaneous. 
TABLE 3

ABSORPTION OF METHANOL BY INHALATION OF THE VAPOUR

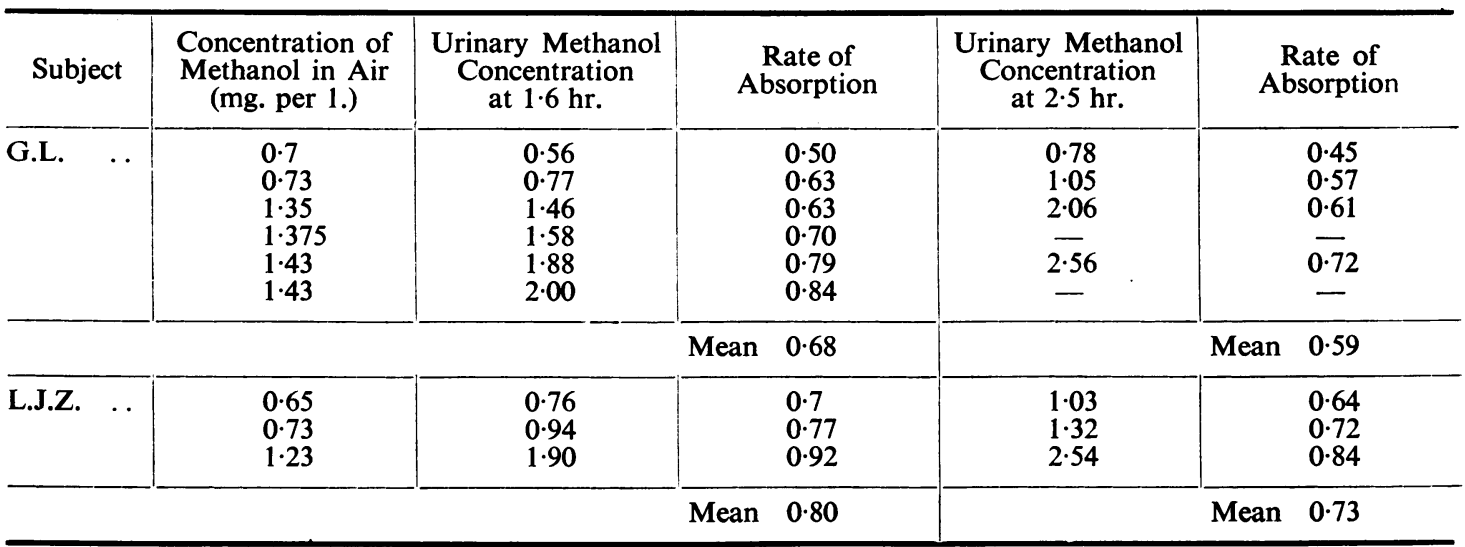

Values for the urinary methanol concentration are in $\mathrm{mg}$. per $100 \mathrm{ml}$., and are corrected for the control value (on entry into chamber). Values for the rate of absorption were obtained by dividing the values in the preceding column by the time and the concentration of methanol inhaled (col. 2).

Only a very small fraction of such doses of methanol appears in the urine ; in different experiments it varied between 0.4 and $1.2 \%$ with a mean of $0.7 \%$. A small number of determinations of the methanol content of the expired air indicated that the loss by expiration was of the same order or slightly larger than the loss in the urine.

Absorption of Methanol by Inhalation.-The increase in urinary methanol concentration during the inhalation of various concentrations of methanol vapour are shown for two subjects in Figs. 4 and 5 . Values for the urinary methanol concentration at 100 and 150 minutes taken from these curves are given in Table 3. On theoretical grounds one would expect the rate of absorption to decrease exponentially with time (Haggard, 1924 ; Gaddum, 1944). The results do show such a trend but the experiments reported are too few and of too short duration to provide useful information on this point. Under the conditions of the experiments exposures of three to four hours were as long as could reasonably be tolerated.

Values for the rate of absorption given in Table 3 show some variation, due in part to the difficulty of controlling the conditions of such an experiment where the subject is also the operator. For the purpose of these experiments, however, it may be taken that under these conditions the rate of absorption for each subject is approximately proportional to the concentration of vapour inhaled.

Effect of Ethanol on Elimination of Methanol.Ingestion of ethanol during the elimination of methanol had a striking effect on the elimination

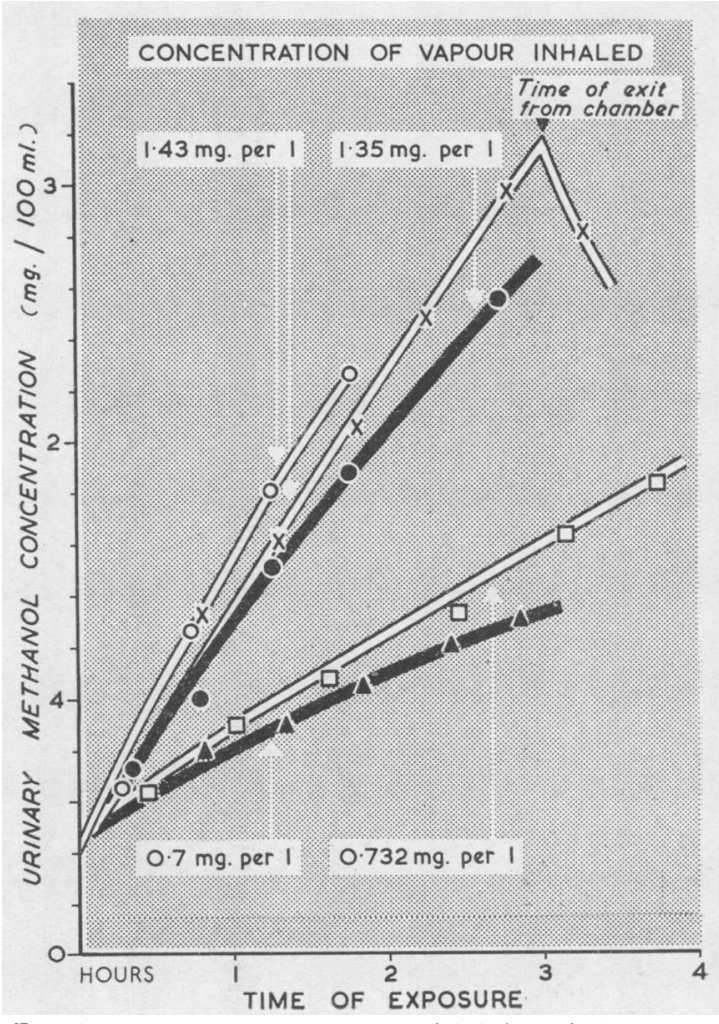

FIG. 5.-Absorption of methanol by inhalation of the vapour. Subject, G.L.

curves. Figs. 6 to 8 show the results of experiments in which ethanol was taken at various times during the elimination of a fixed dose $(4.0 \mathrm{ml}$.) of methanol. 
Other data relevant to these experiments are given in Table 4.

A single dose of $15 \mathrm{ml}$. of ethanol, taken simultaneously with the methanol, caused a marked elevation in the peak concentration of methanol attained (Fig. 6). The time required for the methanol concentration to return to control levels was not obviously affected by such a dose of ethanol. The increase in the peak concentration is attributable to an inhibition by the ethanol of the main process of methanol elimination, i.e. oxidation. The ethanol, however, only operates in this way during the first hour or so of the experiment, since within this time such a dose of ethanol is itself completely eliminated from the body (Eggleton, 1942), so that the total methanol elimination time is not appreciably prolonged. The good reproducibility of the elimination curves in the same subject on different occasions is also illustrated in Fig. 6.

The transient effect of a single dose of ethanol is more clearly seen in Fig. 7. In one experiment the ethanol was taken five hours after the methanol. It effectively arrested the decline in body methanol concentration, which returned to its original rate after about two hours. In another

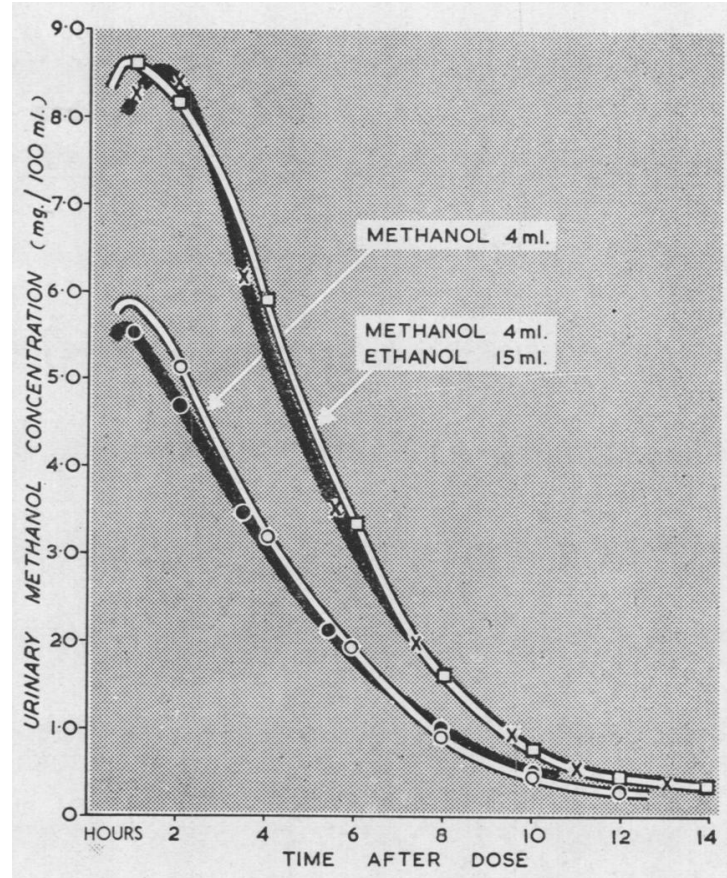

FIG. 6.-The concentration of methanol in urine after ingestion of methanol and of methanol and ethanol simultaneously. Subject L.P.K., weight $63 \cdot 1 \mathrm{~kg}$.

TABLE 4

EFFECT OF ETHANOL ON EXCRETION OF METHANOL IN URINE IN THREE HUMAN SUBJECTS

\begin{tabular}{|c|c|c|c|c|c|c|c|c|c|c|c|c|c|}
\hline $\begin{array}{c}\text { Subject and Body } \\
\text { Weight }\end{array}$ & \multicolumn{2}{|c|}{ A.H.G. } & \multicolumn{2}{|c|}{$67 \cdot 0 \mathrm{~kg}}$. & \multicolumn{5}{|c|}{ L.P.K. $\quad 63 \cdot 1 \mathrm{~kg}}$. & \multicolumn{2}{|r|}{ L.J.Z. } & \multicolumn{2}{|c|}{$57.0 \mathrm{~kg}$. } \\
\hline Date $\quad \ldots \quad \ldots$ & 1.7 .46 & 3.6 .46 & 5.7 .46 & 10.7 .46 & 3.6 .46 & 10.6 .46 & 5.6 .46 & 12.6 .46 & 19.6 .46 & 24.6 .46 & 26.6 .46 & 23.6 .46 & 2.7 .46 \\
\hline $\begin{array}{l}\text { Duration of experi- } \\
\text { ment (hr.) }\end{array}$ & 12 & 12 & 101 & 12 & 12 & 12 & 14 & 13 & 12 & $11 \frac{1}{4}$ & 12 & $12 \frac{1}{3}$ & 12 \\
\hline $\left.\begin{array}{c}\text { Dose } \\
\text { (ml.) }\end{array}\right\} \begin{array}{l}\text { Methanol } \\
\text { (at zero } \\
\text { time) }\end{array}$ & 4 & 4 & 4 & 4 & 4 & 4 & 4 & 4 & 4 & 4 & 4 & 4 & 4 \\
\hline Ethanol .. & None & $\begin{array}{l}15 \text { at } \\
0 \mathrm{hr} .\end{array}$ & $\begin{array}{l}15 \text { at } \\
5 \mathrm{hr} .\end{array}$ & $\begin{array}{c}15 \text { at } \\
0 \mathrm{hr} \text {. } \\
\text { and } 10 \\
\text { each } \\
\text { hr. up } \\
\text { to } \\
7 \mathrm{hr} \text {. }\end{array}$ & None & None & $\begin{array}{l}15 \text { at } \\
0 \mathrm{hr} \text {. }\end{array}$ & $\begin{array}{l}15 \text { at } \\
0 \mathrm{hr} \text {. }\end{array}$ & $\begin{array}{c}15 \text { at } \\
0 \mathrm{hr} \text {. } \\
\text { and } 10 \\
\text { each } \\
\text { hr. up } \\
\text { to } \\
7 \mathrm{hr} \text {. }\end{array}$ & None & $\begin{array}{l}15 \text { at } \\
0 \mathrm{hr} \text {. }\end{array}$ & $\begin{array}{l}15 \text { at } \\
5 \mathrm{hr} \text {. }\end{array}$ & $\begin{array}{l}15 \text { at } \\
4 \frac{1}{2} \text { hr. } \\
\text { and } \\
7 \cdot 5 \text { at } \\
5,5 \frac{1}{2}, \\
6 \text {, and } \\
6 \frac{1}{2} \mathrm{hr} .\end{array}$ \\
\hline $\begin{array}{l}\text { Peak methanol } \\
\text { concentration in } \\
\text { urine (mg. } / 100 \\
\text { ml.) }\end{array}$ & $6 \cdot 05$ & $7 \cdot 95$ & $7 \cdot 21$ & $8 \cdot 82$ & $5 \cdot 50$ & $5 \cdot 12$ & $8 \cdot 60$ & $8 \cdot 35$ & $9 \cdot 20$ & $7 \cdot 27$ & $9 \cdot 75$ & $7 \cdot 70$ & $7 \cdot 20$ \\
\hline $\begin{array}{l}\text { Total volume urine } \\
\text { excreted (ml.) }\end{array}$ & 901 & 1192 & 726 & 1364 & 886 & 885 & 1096 & 857 & 1722 & 496 & 1279 & 479 & 1033 \\
\hline $\begin{array}{l}\text { Total methanol ex- } \\
\text { creted (mg.) }\end{array}$ & $30 \cdot 8$ & $56 \cdot 5$ & $30 \cdot 9$ & $107 \cdot 1$ & $21 \cdot 7$ & $18 \cdot 2$ & $43 \cdot 2$ & $38 \cdot 5$ & $125 \cdot 5$ & $21 \cdot 6$ & $87 \cdot 4$ & $15 \cdot 3$ & $45 \cdot 9$ \\
\hline $\begin{array}{l}\% \text { of dose of meth- } \\
\text { anol excreted }\end{array}$ & 0.97 & $1 \cdot 78$ & 0.98 & $3 \cdot 70$ & 0.68 & 0.57 & $1 \cdot 36$ & $1 \cdot 21$ & 3.96 & 0.68 & 2.75 & 0.48 & 1.45 \\
\hline
\end{tabular}


experiment (Fig. 7) a dose of $15 \mathrm{ml}$. ethanol at four and a half hours was followed by four further doses, each of $7.5 \mathrm{ml}$., at half-hour intervals. The flattening of the curve during this period indicates the arrest of methanol elimination while an adequate concentration of ethanol was maintained in the body. Fig. 8 shows the results obtained in two subjects when a dose of $15 \mathrm{ml}$. ethanol taken with the methanol was followed by hourly doses of $10 \mathrm{ml}$. ethanol for seven hours. Throughout this time the body methanol concentration was maintained at a high level compared

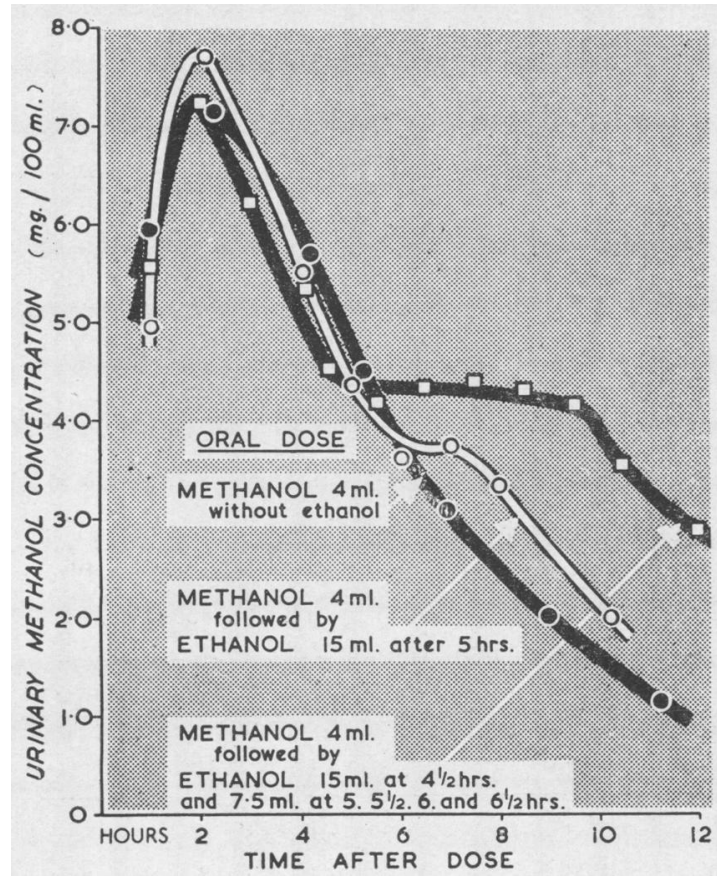

Fig. 7.-The concentration of methanol in the urine after an oral dose of (a) methanol without ethanol (b) followed by ethanol, and $(c)$ followed by two doses of ethanol at specific intervals. Subject L.J.Z., weight $57.0 \mathrm{~kg}$.

with controls without ethanol. It declined slowly, at a rate which might be entirely accounted for by loss of methanol in the urine and expired air. About two hours after the cessation of ethanol administration, when the body ethanol might be expected to be approaching zero again, the decline in methanol concentration accelerated to control levels, indicating the release from inhibition of the chief mechanism of elimination. It is of interest to attempt a quantitative estimate of the effect of ethanol on the rate of elimination of methanol in these experiments. This has been done in Table 5. The data used were taken from the curves of Fig. 8, and refer to a time four hours after the ingestion of methanol, when one may safely assume



FIG. 8.-The concentration of methanol in the urine after an oral dose of methanol (a) without ethanol, and (b) with specificdoses of ethanol simultaneously and hourly for seven hours.

that absorption of methanol from the alimentary tract is no longer a significant factor in determining. the course of the curves. A tangent has been drawn to each curve at the four-hour point, and the slopes of these are given in Table 5 as representing: rates of elimination of methanol. Each, however, is associated with a different body methanol concentration, also given in the table. Evidence has. already been provided that in this concentration

TABLE 5

EFFECT OF ETHANOL ON RATE OF METHANOL ELIMINATION* BY MAN

\begin{tabular}{|c|c|c|c|c|}
\hline \multirow[b]{2}{*}{ Subject } & \multirow[b]{2}{*}{ Dose $\dagger$} & \multicolumn{2}{|c|}{ Methanol Concentration } & \multirow{2}{*}{$\begin{array}{c}\text { Rate of } \\
\text { Fall per } \\
\text { unit of } \\
\text { Magnitude }\end{array}$} \\
\hline & & $\begin{array}{c}\text { Magnitude } \\
\text { (mg./100 } \\
\text { ml.) }\end{array}$ & $\begin{array}{l}\text { Rate of Fall } \\
\text { (mg./100 } \\
\text { ml./hr.) }\end{array}$ & \\
\hline L.P.K. & $\begin{array}{l}\text { (a) } \\
\text { (b) }\end{array}$ & $\begin{array}{l}3.0 \\
8.6\end{array}$ & $\begin{array}{l}0.69 \\
0.21\end{array}$ & $\begin{array}{l}0.23 \\
0.024\end{array}$ \\
\hline A.H.G. & $\begin{array}{l}\text { (a) } \\
\text { (b) }\end{array}$ & $\begin{array}{l}4.6 \\
8 \cdot 35\end{array}$ & $\begin{array}{l}0.77 \\
0.18\end{array}$ & $\begin{array}{l}0.15 \\
0.022\end{array}$ \\
\hline
\end{tabular}

* Data taken from curves of Fig. 8, the figures referring to a time four hours after the ingestion of the methanol.

$+(a)=4 \mathrm{ml}$. methanol ; (b) $4 \mathrm{ml}$. methanol $+15 \mathrm{ml}$. ethanol, and $10 \mathrm{ml}$. ethanol each hour afterwards. 
range the rate of elimination of methanol is proportional to the concentration of methanol in the body. For purposes of comparison, therefore, each rate of elimination has been divided by the corresponding methanol concentration, giving a rate of elimination in mg. per $100 \mathrm{ml}$. per hr. per unit methanol concentration. The reduction of this rate by the giving of ethanol was by $90 \%$ in the case of one subject, by $85 \%$ in the other. This is a rough approximation and it is doubtful if significance should be attached to the difference between the two subjects. It is of interest, however, to note that the figures in Table 5 for rate of elimination per unit methanol concentration show a close correspondence for the two subjects when ethanol was present, whereas in the absence of ethanol L.P.K. appears to have eliminated methanol appreciably more rapidly than A.H.G. Significant individual differences seem less likely in the former case, if only physical processes of elimination dependent on escape in urine and expired air are then operating, than in the latter case when the major process is an enzymic oxidation.

\section{Observations in a Factory}

The methanol synthesis plant formed an offshoot of the ammonia synthesis plant and the actual "methanol converters" in which methanol is synthesized were housed in the same building as the ammonia converters. The converters were used for synthesizing higher alcohols (ethyl, propyl, butyl, etc.), as well as methanol, and conditions could be varied to produce predominantly methanol or a mixture of methanol and higher alcohols. The product of the latter process was separated into higher alcohols and methanol in a distillation plant referred to as the " stripping plant". The methanol from this distillation and from the other process was refined in the "methanol distillation plant". The atmosphere was sampled in all three places mentioned, and urine samples were taken from workers in the methanol distillation and stripping plants. A brief description of conditions of testing in each case is given below.

The air was analysed as described under "Methods". The air-inlet of the sampling train was placed in positions most likely to give a concentration of methanol vapour in a place habitually frequented by the operatives. Fairly long sampling periods (two to six hours) were used so as to yield a measure of the average concentration at the position chosen. The results are shown in Table 6.

Synthesis Plant.-In this case the air inlet was suspended at a height of about $7 \mathrm{ft}$. from the wiremesh working platform at a point situated between the sampling tray (which was equipped with taplines from the plant, by means of which samples were taken approximately hourly) and the control panel where the operatives spent most of their time. The air was tested during the day and once during the night shift. As the building was very spacious and the plant a high pressure one, i.e. working at a high pressure, therefore completely closed in, the negative results appended are not surprising.

Methanol Distillation Plant.-In this case the "still" and storage tanks were in the open air, whilst the control panel which the operatives attended was housed in a small building. The "sampling tray" was housed in a small passage along the back of this building, and although the operatives generally entered this part only once an hour to take samples, the air-inlet was placed close to the sampling tray as this was the most likely place to find an accumulation of methanol vapour. In this instance urine samples were taken at the beginning and end of shifts from six workers over

TABLE 6

RESULTS OF AIR ANALYSIS AT I.C.I. METHANOL SYNTHESIS PLANT

\begin{tabular}{|c|c|c|c|c|c|c|c|}
\hline \multicolumn{3}{|c|}{ Site } & \multicolumn{3}{|c|}{$\begin{array}{c}\text { Duration of } \\
\text { Sampling }\end{array}$} & \multirow{2}{*}{$\begin{array}{c}\begin{array}{c}\text { Volume of Air } \\
\text { Entrained }(\mathbf{C})\end{array} \\
277 \\
254 \\
175 \cdot 5 \\
378\end{array}$} & \multirow{2}{*}{$\begin{array}{c}\begin{array}{c}\text { Methanol } \\
\text { Concentration } \\
\text { (p.p.m.) }\end{array} \\
<5 \\
\text { ", } \\
\text { ", }\end{array}$} \\
\hline (1) & Synthesis plant & $\ldots$ & $\begin{array}{r}11.40 \\
2.35 \\
11.25 \\
10.30\end{array}$ & $\begin{array}{l}\text { a.m.- } 2.25 \\
\text { p.m.- } 4.30 \\
\text { p.m.- } 2.30 \\
\text { a.m.- } 4.35\end{array}$ & $\begin{array}{l}\text { p.m. } \\
\text { p.m. } \\
\text { a.m. } \\
\text { p.m. }\end{array}$ & & \\
\hline (2) & Methanol distill & n plant.. & $\begin{array}{r}11.02 \\
1.58\end{array}$ & $\begin{array}{l}\text { a.m.- } 1.43 \\
\text { p.m.- } 5.05\end{array}$ & $\begin{array}{l}\text { p.m. } \\
\text { p.m. }\end{array}$ & $\begin{array}{l}357 \\
248\end{array}$ & $\begin{array}{l}40 \cdot 5 \\
64 \cdot 0\end{array}$ \\
\hline & Stripping plant & $\ldots$ & $\begin{array}{r}10.30 \\
12.17 \\
1.53\end{array}$ & $\begin{array}{l}\text { a.m.-12.05 } \\
\text { p.m.- } 1.46 \\
\text { p.m.- } 4.08\end{array}$ & $\begin{array}{l}\text { p.m. } \\
\text { p.m. } \\
\text { p.m. }\end{array}$ & $\begin{array}{l}133 \cdot 3 \\
136 \cdot 5 \\
156\end{array}$ & $\begin{array}{r}82 \\
116 \\
80\end{array}$ \\
\hline
\end{tabular}


three days. The analysis of all samples gave negative results except for two end-of-shift samples from one worker. The concentration found in these two cases were so small, however, as to be almost negligible.

Stripping Plant.-This plant smelt worst of the three, though the smell was due to uncharacterized "volatile oils" separated in the distillation process. The housing containing the sampling trays, and control panels was built round the columns of the still some height above ground level. The air inlet was suspended in this case close to the control panels, one sample being taken at a remote sampling tray and the other two being taken from the space between two other sampling trays where the operatives had table and chairs and spent most of their time. Samples were taken hourly. Urine samples were taken at beginning and end of shifts from three workers for three days and the results of analysis were again negative.

\section{Discussion}

Assessment on Safety Limits for Exposure to Methanol Vapour.-The initial aim of these experiments was to find the threshold for methanol accumulation by finding (1) how much methanol a man could eliminate within 16 hours, and (2) the concentration of methanol vapour which must be inhaled for eight hours to cause the retention of such an amount in the body.

The experiments on the elimination of orally administered methanol showed that after the lapse of sufficient time for complete absorption, the rate of elimination was proportional to the concentration of methanol in the body water. The mechanism of elimination is discussed below, but for the present purpose the finding that elimination follows the equation

$$
\log \mathrm{C}=\log \mathrm{C}_{\circ}-\mathrm{kt}
$$

allows us to calculate the urinary methanol concentration $\left(\mathrm{C}_{\mathrm{o}}\right)$ corresponding to an amount of methanol which may be disposed of within 16 hours. If elimination is considered to be complete when $\mathrm{C}=0.5 \mathrm{mg}$. per $100 \mathrm{ml}$. (average blank value for these experiments), substitution of the observed magnitudes for $\mathbf{k}$ in the above equation gives values for $C_{\circ}$ of $19 \cdot 1,21.5$, and $21.6 \mathrm{mg}$. per $100 \mathrm{ml}$. for subjects G.L., H.S.R., and L.J.Z. respectively. As the urinary methanol concentration has been shown to be a satisfactory index of the concentration of methanol in the body, these values can be used directly without further manipulation. The degree of exposure giving rise to such urinary methanol concentrations may be estimated using the results of the inhalation experiments. The rates of absorption of methanol observed in experiments are much lower than those observed with smaller animals. Loewy and von der Heide (1914) found a methanol content of $45 \mathrm{mg}$. per $100 \mathrm{~g}$. in the bodies of rats exposed to a vapour concentration of 2,000 p.p.m. for two hours. The inhalation of methanol vapour at half this concentration $(1 \cdot 35$ mg. per 1., 1015 p.p.m.) by G.L. gave rise to a urinary methanol concentration of $2.4 \mathrm{mg}$. per $100 \mathrm{ml}$. corresponding to an even smaller concentration in the body as a whole. Yant and Schrenck (1937) found blood methanol concentrations of 84 to 100 mg. per $100 \mathrm{~g}$. in dogs exposed to a methanol concentration of 4,000 p.p.m. for 12 hours which suggests an average rate of absorption at least three times as great as the rates observed here. These discrepancies emphasize the necessity for carrying out such experiments on man rather than on the usual experimental animals.

The values for the rate of absorption of methanol given in Table 3 may be used to estimate the methanol vapour concentration, by exposure to which for eight hours the two subjects would attain the critical body methanol content represented by the $C_{0}$ values calculated above. For G.L. the rate of absorption was found to be 0.59 ; the critical vapour concentration for this subject would therefore be

$$
19.1 / 8 \times 0.59=4.04 \mathrm{mg} \text {. per } 1 \text {. or 3,050 p.p.m. }
$$

The corresponding calculation for L.J.Z. gives $3.70 \mathrm{mg}$. per 1 . or 2,780 p.p.m.. For these two subjects, therefore, a concentration of approximately 3,000 p.p.m. of methanol would involve a danger of gradual accumulation of methanol in the body.

The accuracy of these estimates is limited chiefly by the accuracy of the determined rates of absorption which are based on rather few experiments. Extrapolation of the results of these experiments to cover a period of eight hours may involve some error, but in so far as the rate of absorption may be expected to fall as the duration of exposure increased, the critical vapour concentration would be underestimated rather than overestimated. On the other hand, in using these data to judge conditions in industry, it must be remembered that during the inhalation experiments the subjects were in a comparatively resting state. Vigorous activity by stimulating respiration would probably increase the rate of absorption and increase the hazard. Further, as industrial conditions are more difficult to control than those in the laboratory, the permissible maximum concentration should be set at a much lower level, say $10 \%$ of the above, i.e. 300 p.p.m. Below this level accumulation is very unlikely to occur, and so far no untoward symptoms have been observed with doses liable to be absorbed 
at this level. On this basis safety limits which have previously been proposed, e.g. 100 p.p.m. by the International Labour Office and 200 p.p.m. by von Oettingen (1943), leave a good safety margin.

In the light of these considerations the conditions prevailing in the factory which was investigated were quite adequately controlled and ensured freedom from potential harm for the operators. In positions where the highest vapour concentrations may be expected the average vapour concentration exceeded 100 p.p.m. in only one test. As the men only spent a proportion of the shift in these immediate areas, the presence of no more than traces of methanol in their urine is understandable. This, in turn, confirms that the value suggested above for the maximum permissible concentration of methanol vapour leaves an adequate safety margin. It must be pointed out, however, that the factory investigated was designed with an awareness of the hazard of methanol poisoning, and these observations do not preclude the possibility of danger arising on less well-controlled premises.

Effect of Ethanol on Elimination of Methanol.Previous work on the elimination of methanol has been carried out on animals other than man and has yielded conflicting results. Neymark (1936) and Neymark and Widmark (1936) claimed that the rate of elimination from dogs was independent of the dose level. Haggard and Greenberg (1939), on the other hand, concluded that in rats and dogs the rate of elimination was proportional to the concentration of methanol in the body. According to the latter workers the greater part of the ingested methanol was excreted in the expired air as a result of simple diffusion, and the rate of excretion was therefore directly proportional to the concentration in the blood. Using rats, they recovered from the expired air $70 \%$ of the methanol which had disappeared from the body, in an experimental period during which, however, only $6 \%$ of the whole dose was eliminated. Asser (1914) and Völtz and Dietrich (1912) found, respectively, 53\% and 30\% of the dose excreted in the expired air of dogs.

In the present work the experiments on man showed that, after the lapse of sufficient time to ensure complete absorption, the rate of elimination of methanol was proportional to its concentration in the body water, and in this respect the findings of Haggard and Greenberg were confirmed, but excretion via the lungs does not appear to have played a major part. Rough calculations using Haggard and Greenberg's formula suggest that the elimination of such doses of methanol via the expired air alone would have taken several days whereas in fact 12 to 16 hours were found sufficient.
As the urinary loss represented on the average less than $1 \%$ of the dose taken, and respiratory loss little more, it is clear that metabolic processes must have been chiefly responsible for the disappearance of methanol from the body. By appropriate administration of ethanol, it was found possible to reduce the rate of methanol elimination by about $90 \%$. This striking effect cannot be attributed to any action of ethanol on the purely physical processes of elimination of methanol via lungs or kidney, and it therefore identifies the main methanol eliminating process under the conditions of our experiments and in the absence of ethanol as a metabolic process. Further support for this view can be found in the data recorded in Table 4. The fraction of the methanol which appears in the urine is actually increased by the presence of ethanol. A single simultaneous dose of ethanol increased the fraction excreted from $0.7 \%$ to $1.8 \%$ and repeated ingestion of ethanol raised it to almost $4 \%$. (These values are averages of the results from the appropriate experiments in Table 4.)

The disagreement with Haggard and Greenberg as regards the relative importance of respiratory elimination may readily be resolved when the difference in dosage is taken into consideration. Haggard and Greenberg gave doses of 1 to $4 \mathrm{~g}$. per $\mathrm{kg}$., far greater than can be used in experiments on man. In the present work doses of from 0.029 to $0.084 \mathrm{~g}$. per $\mathrm{kg}$. were used. It is most probable that at low body methanol concentrations the alcohol is removed chiefly by an enzymic reaction. With increasing concentration, a limit to the rate of removal by this route is reached when the enzyme becomes saturated with its substrate. Urinary and respiratory elimination are never restricted by such a limit and at a sufficiently high methanol concentration must be expected to play a dominant part. The exponential nature of the methanol elimination curves in our experiments suggests that the prevalent methanol concentration was well below that required to saturate the enzyme, falling in the region where reaction is roughly proportional to substrate concentration.

There is no reason to doubt that the enzymic removal of methanol is achieved by a process of oxidation. Lutwak-Mann (1938) demonstrated the ability of horse liver alcohol dehydrogenase to oxidize methanol, as well as ethanol, to the corresponding aldehyde, but found the rate of reaction to be much slower in the former case. The conversion of methanol to formaldehyde by alcohol dehydrogenase in vitro has been confirmed, and ethanol has been shown to exert a powerful competitive inhibitory effect on this oxidation. Inhibition was almost complete when the molar ratio of 
ethanol to methanol was as little as 1 to 15 . This appears to justify the suggestion that the in vivo effects of ethanol on methanol elimination were due to an inhibition of the oxidation of methanol by alcohol dehydrogenase. Eggleton's observations (1942) indicate that the peak blood ethanol concentration in man after a dose of $15 \mathrm{ml}$. is about $30 \mathrm{mg}$. per $100 \mathrm{ml}$., and that about $10 \mathrm{ml}$. of ethanol are metabolized per hour at such concentration levels. The method of recurrent ethanol administration adopted in our experiments might be expected therefore to maintain a body ethanol concentration high enough to suppress methanol oxidation.

In a later review of 83 cases of methanol poisoning Røe (1946) felt confirmed in his earlier (1943) impression that the toxic symptoms of methanol poisoning, particularly the amblyopia, tended to be minimized by the concurrent drinking of ethanol (see also Dérobert and Hadengue, 1949). There is a widespread belief that these toxic effects are not caused by methanol itself, but by a metabolic product, probably formaldehyde and/or formate (Keeser, 1931 ; Keeser and Alberty, 1948 ; Flury and Wirth, 1936 ; Fink, 1943 ; Røe, 1943, 1946). Evidence in support of this view has been obtained by experiments with surviving retina (to be reported elsewhere). It was found that methanol had no effect on the metabolism of ox retina even at a concentration of $\mathrm{M} 20$. Of the metabolic products of methanol, formate had a weak inhibitory effect on retinal respiration and formaldehyde strongly inhibited both aerobic respiration and anaerobic glycolysis.

Asser (1914) had previously found that simultaneous administration of ethanol, amyl alcohol, or acetone reduced the urinary excretion of formate by dogs after the ingestion of methanol, an effect recently confirmed by Bastrup (1947) in dogs and rabbits, but he concluded that these substances did so by increasing the permeability of cell membranes to formate thus facilitating further oxidation of this product. Røe suggests an alternative explanation, that the diminished excretion of formate was caused by a reduction in the rate of formation due to the capacity of ethanol " to displace methanol from the surface of cells, its oxidation to formic acid being thereby checked". More recently Agner and Belfrage (1947) observed a decreased rate of fall of the blood methanol concentration after the simultaneous injection of ethanol in rabbits. This observation and our own results provide a more rational basis for explaining a favourable effect of ethanol as the result of an inhibition of methanol oxidation, and might justify attempts to use ethanol therapeutically in methanol poisoning in an endeavour to maintain the inhibition long enough to secure elimination of the methanol unchanged by the respiratory and urinary routes. Such a use of ethanol has indeed recently been reported by Agner, Höök, and von Porat (1949). Only two patients were treated, however, and of these, one recovered and one died.

It is perhaps significant that only two or three cases of blindness have been reported from the drinking of methylated spirits in this country, although the drinking of this spirit is apparently quite widespread. The above results suggest that the large proportion of ethanol in the spirit (about $95 \%$ ) would indeed reduce very markedly the toxic effects of the methanol.

\section{Summary}

Owing to the slow rate of elimination of methanol from the body, repeated exposure to the vapour or liquid may result in accumulation and under such conditions the use of methanol would constitute a toxic hazard. The present work was carried out in order to determine the maximum concentration of methanol vapour, exposure to which for eight hours is consistent with complete elimination of absorbed methanol during the subsequent 16 hours. The absorption and elimination of methanol were therefore studied in man.

The concentration of methanol in the body was followed by determination of the concentration in the urine. The reliability of this procedure was confirmed by experiments with the cat and with human subjects.

The elimination of methanol after doses of 2.5 to $7.0 \mathrm{ml}$. has been studied in five human subjects. At any time the rate of elimination was found to be proportional to the concentration of methanol in the body. The significance of this finding is discussed. Only a very small fraction of the ingested methanol (about 2\%) was eliminated via the respiratory and urinary routes.

The rates of absorption of methanol by two human subjects during exposure to vapour concentrations of 0.6 to $1.5 \mathrm{mg}$. methanol per 1 . (400-1,000 p.p.m.) have been investigated. Over short periods the amount of methanol absorbed appears to be approximately proportional to the duration of exposure and to the concentration of vapour in the atmosphere.

By examination of the results of the absorption and elimination experiments it was concluded that exposure to a methanol vapour concentration of about 3,000 p.p.m. for eight hours a day may cause accumulation of methanol in the body and thus give rise to a toxic hazard. It is suggested that the maximum concentration of methanol 
vapour to which workers may be safely exposed is 300 p.p.m.

Observations made at the methanol synthesizing plant of I.C.I. Ltd. are described. Estimation of the methanol concentrations in the air and in the urine of the operatives showed that conditions were satisfactorily controlled.

The ingestion of ethanol, together with or shortly after methanol, reduced the rate of elimination of the latter by up to $90 \%$. Evidence is adduced to show that this is due to inhibition of the metabolic oxidation of methanol.

These results provide a rational basis for explaining the favourable effect of ethanol on the course of methanol poisoning such as $\mathrm{R} ø \mathrm{e}$ reports, and might justify attempts to use ethanol therapeutically.

We should like to express our sincere thanks to the late Professor H. S. Raper, C.B.E. and Dr. L. P. Kendal for their constant interest in this work and their assistance as experimental subjects ; to Professor A. A. Harper, for assistance with the cat experiments, and to Dr. A. H. Gowenlock for being an experimental subject. Our thanks are also due to Dr. Schilling and Messrs. I.C.I. Limited for arranging the investigations at Billingham.

The cost of this work was partly defrayed by the Medical Research Council, to which we are also grateful for a grant to one of us (L.J.Z.).

\section{REFERENCES}

Agner, K., and Belfrage, K. E. (1947). Acta. physiol. scand., 13, 87. Höök, O., and von Porat, B. (1949). Quart. J. Stud. Alcohol, 9,515 .

Asser, E. (1914). Z. exp. Path. Ther., 15, 322.

Bastrup, J.T. (1947). Acta pharmacol, 3,3

Browning. E. (1937). Med. Res. Coun. Industrial Health Research Board. Rep. no. 80.

Carpenter, T. M. (1940). Quart. J. Stud. Alcohol, 1, 201.

Chew, W. B., Berger, E. H., Brines, O. A., and Capron, M. J. (1946) J. Amer. med. Ass., 130, 61 .

Denigès, G. (1910). C.R. Acad. Sci., Paris, 150, 529, 832.

Dérobert, L., and Hadengue, A. (1949). Chem. Abstr., 43, 3105.
Egg, C. (1927). Schweiz. med. Wschr., 8, 5. Eggleton, M. G. (1940). J. Physiol, Lond., 98, 228, 239. - (1942). Ibid., 101, 172.

Fink, W. H. (1943). Amer, J, Ophthal. 26, 694.

Flury, F., and Wirth, W. (1936). Arch. Gewerbepath. Gewerbehyg., $7,221$.

Gaddum, J. H. (1944). Nature, Lond., 153, 494.

Haggard, H. W. (1924). J. biol. Chem., 59, 753.

- , and Greenberg, L. A. (1934). J.'Pharmacol., 52, 150, 167, - - (1939). Ibid., 66, 479. , Carroll, R. P., and Miller, D. P. (1940). J. Amer. med. Ass., 115, 1680.

Hamilton, A. (1925). "Industrial Poisons in the United States." New York

Harger, R. N., Hulpieu, H. R., and Lamb, E. B. (1937). J. biol. Chem., 120, 689.

Humperdinck, K. (1941). Arch. Gewerbepath. Gewerbehyg., 10, 569.

Jacobson, B. M., Russell, H. K., Grimm, J. J., and Fox, E. C. (1945). Nav. med. Bull., Wash., 44, 1099.

Kaplan, A., and Levreault, G. V. (1945). Ibid., 44, 1107.

Keeser, E. (1931). Arch. exp. Path. Pharmak., 160, 687.

-, and Alberty, J. (1948). Klin. Wschr., 26, 212.

Loewy, A., and von der Heide, R. (1914). Biochem. Z., 65, 230

Lutwak-Mann, C. (1938). Biochem. J., 32, 1364.

McCord, C. P. (1931). Industr. Engng. Chem., 23, 931.

McGregor, I. S. (1943). Brit. J. Ophthal., 27, 523.

Macht, D. I (1920).J. Pharmacol, 16, 1.

Munch, J. C., and Schwartze, E. W. (1925). J. Lab. clin. Med., 10, 985 .

Neymark, M. (1936). Skand. Arch. Physiol., 73, 227.

and Widmark, E. M. P. (1936). Ibid., 73, 283.

Nicloux, M. (1934). Bull. Soc. Chim. biol., Paris, 16, 330.

Le Breton, E., and Dontcheff, A. (1934). Ibid., 16, 1314 and Placet, A. (1912). J. Physiol. Path. gén., 14, 916.

Oettingen, W. F. von (1943). "The Aliphatic Alcohols." U.S. Pub. Health Service, Pub. Health Bull. No. 281. Govt. Ptg. Office, Washington.

Poulsson, E. (1941). “Lehrbuch der Pharmakologie," 12th ed. Leipzig and Oslo.

Richardson, B. W. (1869). Med. Times, Lond., 2, 703.

Røe, O. (1943). Acta. med. scand., 113, 558.

Røs, O. (1943). Acta. med. scand.,

Rost, E., and Braun, A. (1926). Arb. ReichsgesundhAmt., 57, 580

Sayers, R. R., Yant, W. P., Schrenk, H. H., Chornyak, J., Pearce, S. J., Patty, F. A., and Linn, J. G. (1944). J. industr. Hyg., 26, 255 .

Scott, E., Helz, M. K., and McCord, C. P. (1933). Amer. J. clin. Path., 3, 311 .

Tyson, H. H., and Schoenberg, M. J. (1914). J'Amer. med. Ass., 63,915

Uhthoff, W. (1915). Klin. Mbl. Augenheilk., 54, (I), 48.

Völtz, W., and Dietrich, W. (1912). Biochem. Z., 40, 15.

Weese, H. (1928). Arch. exp. Path. Pharmak., 135, 118.

Widmark, E. M. P. (1933). Biochem. Z., 259, 285.

Widmark, E. M. P. (1933). Biochem. Z., 259, 285.

Witte, R. (1933). Arch. Gewerbepath. Gewerbehyg., 5 ,

Wright, L. O. (1927). Industr. Engng. Chem., 19, 750.

Yant, W. P., and Schrenk, H. H. (1937). J. industr. Hyg., 19, 337.

Zatman, L. J. (1946). Biochem. J. Proc., 40, Ixvii.

Ziegler, S. L. (1921). J. Amer. med. Ass., 77, 1160. 